\title{
SOCIAL FACTORS INFLUENCE FROM THE PERSPECTIVE OF DENTAL HEALTHCARE SERVICES CONSUMERS' BEHAVIOR
}

\author{
Iuliana Petronela Gârdan \\ Spiru Haret University, Bucharest, Romania \\ gardanpetronela@yahoo.com \\ Daniel Adrian Gârdan \\ Spiru Haret University, Bucharest, Romania \\ danielgardan@yahoo.com \\ Gheorghe Epuran \\ University Transilvania of Braşov, Braşov, Romania \\ epuran.gheorghe@unitbv.ro
}

\begin{abstract}
In case of dental care consumption, a very special influence will have the social factors. This influence, from the level of consumers' behavior can be analyzed on two distinct levels - that of normatives impose by the social organization particular for the community that the individual live and that of the influences of the social groups that individual are interacting with. Dental healthcare services consumption is conditioned at the level of consumption motivations by complex needs which are not confined only to the physiological needs of removing pain caused by a certain dental condition, but are going towards the need of self-image improvement, increasing the appreciation offered by the others group members, the congruence with other consumers decisions within the group (family members, friends, colleagues etc). It is important to note in this context the fact that the influence exerted by consumers exogenous factors (external influences in which we can integrate those from the social groups also) will be combined with the one exerted by endogenous factors (personality, learning process, perceptions, attitudes, motivations etc), representing a continuum that shape consumers and allows in the same time the society shaping by them. The present article proposes a research conducted on dental healthcare services consumers. Results revealed the importance that a series of variables like the importance given to image in the workplace, family, friends and colleagues perception towards dental aesthetic, social class has in the context of consumer behavior. It is also noted that the influence of variables is mediated by the importance given to self-image, dental healthcare services consumption being determined by complex needs, consumption motivations being physiological - specific to some medical conditions and psychological - aesthetic or induced by the pressure corresponding to the need to comply with social norms.
\end{abstract}

\section{Keywords}

Consumer behavior, dental healthcare services, social factors, self-image

\section{JEL Classification}

M31

\section{Introduction}

Consumer behavior represents a complex assembly of processes being interrelated with each other. In the same time it is the result of internal nature factors and external factors, exogenous to the individuals. Processses like perception, motivation, learning, attitudes and personality formation are interrelated and are defining the behavior manifestation. Thus all the exogenous factors like family, belonging groups, reference 
groups, social class, culture and subculture will be correlated with the endogenous factors.

The consumer behavior represents a continuum that involves multiple transformations and a perpetual reference to the environmental changes. As a result, social influences exert their action on multiple fronts - exogenous through the direct influence upon individuals and their answer in order to have a better integration within the assembly of a group norms (belonging or reference), endogenous through complex processes of changing preferences or needs, as a result of different pressures related with social conventions and the joint action of cultural elements.

The social interactions presuppose generative relations that induce changes of perceptions and automatically changes at the level of consumers' actions. The individuals found themselves all the time in an evolving, historic and institutional context, therefore we have to analyse the consumption or buying behavior taking account of this context.

From this point of view it has to be mentioned the importance that interactions between individuals and institutions could have in this context. Institutions can be defined like being durable social rules and intrinsic conventions systems which are structuring social interactions (Hodgson, G.M., 2003, p. 166).

Money, the legal system, system of measurements, companies, all of this represents institutions whose durability is given by the fact that ussualy they can create stable expectations at the level of others behavior. Actually the sum of habits that can be developed are determined by the interactions with these institutions and in the same time they can contribute to the very functioning of these institutions. The habits represent the base for both the reflective behavior and for the unreflective one, and are representing essentially a trend that can be easily transformed in a complex of actions and determine the occurrence of a particular behavior.

This duality of exogenous and endogenous influences upon consumers' behavior sketched a complex landscape that highlights the evolution of social structures from the very dawn of civilization until today. Humans can not escape the social framework in which they develop from an early age. In turn, this social framework with all its institutions, social groups of influence, etc., is the effect of human activities and acts of consumption and choices that individuals typically have.

From the point of view of healthcare services consumption, these social interactions have new meanings, given by the specific of healthcare services and the needs that are behind consumption motivations.

The evolution of healthcare systems itself it's determinated by the choices that consumers are doing and the behavior that is related with influence groups.

On a long run, the consumption processes will self-regulate, and the efficiency of prestations will rise into the direction of a better serving of the social interest. All the spectacular transformations of the modern medical technology, treatment methods and techniques, stand as witnesses of the fact that the social needs combined with individual health care needs of individuals have shaped this area and continue to shape it.

In the case of dental healthcare services, we may encounter a consumer behavior largely oriented toward a conspicuous consumption, because of the very high level of the prices, and some exclusive services (regarding dental aestetique). This kind of conspicuous consumption may be trying to affirm also the social status of the person concerned.

The dental healthcare services consumption motivations found themselves in the zone of self-image improvement and level of appreciation from others. For this reason the consumer behavior may become atypical - in relation with the purchasing power or other repetitive consumption decisions that the concerned persons can manifest. 
Also, given the strong emotional involvement in the case of dental care services, the consumers will have the tendency to seek for the others approval and to integrate themselves in the current opinion stream of the belonging or reference groups.

Because of the high pressure regarding the consumption decision process, any healthcare service is situated into the zone of consumption influenced by the the opinions of family members or acquaintances. In comparison with other type of services or products, the need of information regarding their own consumption from the members of the reference groups is bigger. In the same time individuals may show a more intense communication with the members of the group in order to connect with the norms and values of the group.

\section{Literature review concerning influence of socio-economic factors upon the healthcare services consumers' behavior}

Generally speaking, consumption can be seen according to the paradigm proposed by Veblen as being a social activity constrained by social norms and the structure of social classes.

From this point of view the relationship between social norms, social groups, social classes, cultural and subcultural traits and consumers' behavior represents an intrinsic reality based on the social nature of relationships between individuals, and the different types of needs.

The well known economist Thorstein Veblen has point out even from 1889 in his works the fact that in the case of conspicuous consumption, individuals will use it as a mean to express the welfare, power and social status. (Vigneron, F., \& Johnson, L., 1999, p. 5).

Other specialists point out the fact that the consumption of products that have very high prices is motivated socially, consumers tend in this case to associate these high prices to the prestige and status (Berkowitz, E.N., Kerin, R.A., Hartley, S.W., \& Rudelius, W., 1992, p. 37).

The conclusion can be that conspicuous consumption is ussualy associated with prestigious products and services, the main motivation asscoiated with this type of consumption beeing the wish of individuals to transmit clear informations to the others regarding their social status.

The social status is very close related with the role that every individual will assume within the social frame. These roles are developed by individuals within the social groups that they belong, being associated with a certain image and value granted by the other members of the group. There will be brands and products or services that will have from the perception of the consumers the capacity to communicate a certain status, a certain relationship capacity. Thus, people will have the tendency to consume products or services capable to sustain their status and to express their social value (Vigneron, F., \& Johnson, L.W., 1999, p. 3).

Every member of a social group will observe the consumption models of other members from society. In this process, comparisons are made in order to judge the relevant elections of the others and their belonging to a certain status (Reinstaller, A., \& Sanditov, B., 2005, p. 505-531). Thereby, the consumer behavior will be determined by the degree in which every individual will be sensible in terms of interpersonal influence (Bearden, W., Netemeyer, R.G., \& Teel, J.E., 1989, p. 473-481).

The social relations and the status will be than interrelated and both can influence the predispozition of consumers for different type of behavior. (Dittmar, H., 1994, p. 561585)

In order to express themselves, individuals will adopt different lifestyles and specialists observe that the lifestyle adopted is common with the social group representative for the individual. (Starr, M.A., 2009, p. 25-49). 
In case of healthcare services consumption, the consumer behavior will be influenced in a very specific way by social factors. This is due to the characterisitics of healthcare services in the first place and also due to the very specific features of the needs related with health issues.

Social and cultural factors will interact with biological features of every individual and will impact the health condition. From this respect "the Sociocultural Model" will encompass elements reffering to: the health and ilness definition of individual and the personal experience regarding this topic, acces to healthcare, the individual response to disease, pain and/or disability, treatment expectations and options, health outcomes (Uskul, K.A., 2010).

The social determinants reffering to the social norms and social groups beliefs, customes, values etc, will shape the attitude of consumers regarding healthcare and even the healthcare practices specific for a certain region or community. (Hahn, A.R., \& Harris, W.K., 1999)

In case of dental healthcare services the positioning of these services at the level of the Romanian market is associated with high prices services due to the level of the prices in comparison with other type of services. Thus, the consumption related with these services will have the characteristics of a conspicuous one especially for the dental aesthetics services.In this case choosing a certain dental office, having a well established brand image in the premium sector of the market will represent a way to emphasize the social status of the consumer.

\section{Reasearch methodolgy}

The research falls within the category of descriptive research. In the case of present research it was used the specific research method based on a field survey questionnaire that represents an established method for this type of research.

Primary information sources are specially made to achieve the objectives of this research, being any person aged 18 years, residing in Bucharest that has resorted to an dental office or clinic in the last 6 months. The sampling consists of persons over 18 years because generally is considered that they can take the decision to purchase. The final number of respondents was 356 persons.

The research aimed to identify, describe and analyze the main dimensions of the influence exerted by social norms and economic factors upon dental care services consumer behavior.

As research hypotheses have been advanced the following:

- There is a very strong influence of family, friends or colleagues on the patient's decision to consume a particular dental office services.

- Dental care consumption is determined by the importance of self image;

- There is a strong correlation between social factors and the importance given to selfimage;

- Membership of a certain social class can determine how dental health services are consumed;

- Social status determines a different consumer behavior for dental health services

- Romanian consumers were affected by the reduction of incomes having in the background the economic crisis which has affected the consumption of dental healthcare services.

After administration of questionnaires, univariate and multivariate analysis of information obtained was done through statistical and mathematical analysis software package IBM SPSS 20.0 


\section{Research results}

One of the research objectives was related with the determination of belonging and reference groups influence degree upon the consumer behavior. The respondents have been asked about their perception related to the degree in which the way that they are perceived by the family members, friends or colleagues relted with their dental aesthetic counts. The medium score of 4,045 measured with the help of semantic differential scale shows the great importance that the respondents gave to the perception of social groups about their dental aesthetic.

Another research objective was to determine consumer perceptions in regard to possible changes in healthcare services consumers' behavior due to changes in the patients' self-image.

The results of the research are showing that the majority of respondents were not affected by major self-image changes as a result of everyday interactions beause of dental diseases.

Thus, it is possible to exist a dispersion high enough of the severe cases throughout the responses, the phenomenon being normal for a statistics population of normal individuals from a dental medical standpoint (not presenting a bias or an excess incidence of medical very serious cases).

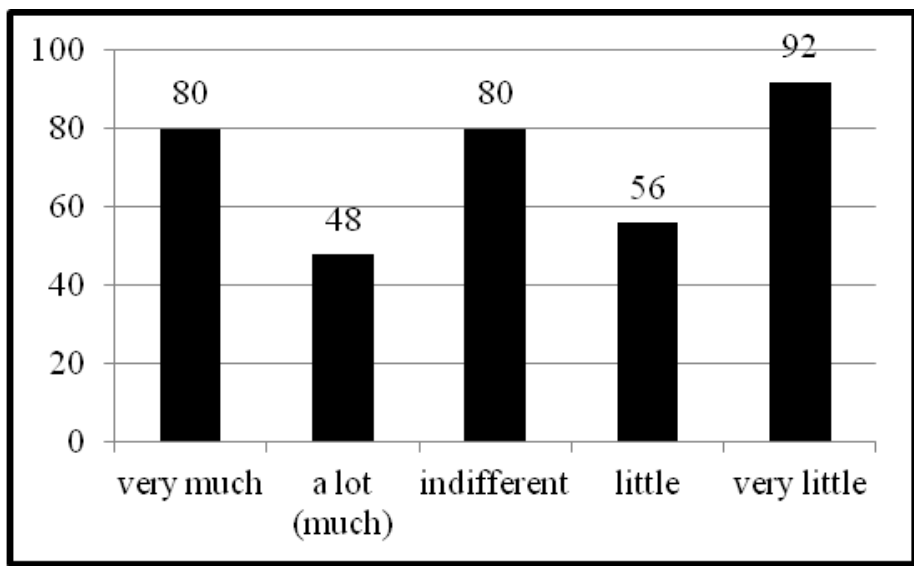

Figure 1. The degree in which the dental problems affect respondents' daily life

In the case of the extent to which consumption of dental medical servicesis determined by the importance of self-image obtained a score of 3.865 on a differential scale which indicates that the opinion of respondents is that the consumption of dental medical services is largely determined by the importance of the self-image. This result confirms one of the research hypothesis reffering to the degree in which dental medical services consumption is determined by the importance of self-image. Overall, the self-image represents a very important element within the psihic life of any mentally healthy individual. Therefore responses are important because not only confirms this information that was ample tested in scientific literature from the psychology field (Marsh, 1986; Sirgy, 1982; Baumeister, Campbell, Krueger, Vohs, 2003; Ciarrochi, Heaven, Davies, 2007), but reveals also the fact that self-image is linked with oral health state and appearance of the patients mouthparts.

Most of the respondents did not suffer from serious illnesses to the present date (59\%), but of those who suffered serious condition most of them have been affected by the difficulty to smile (21\%), followed by those who have speaking or chewing difficulties (12\%). 


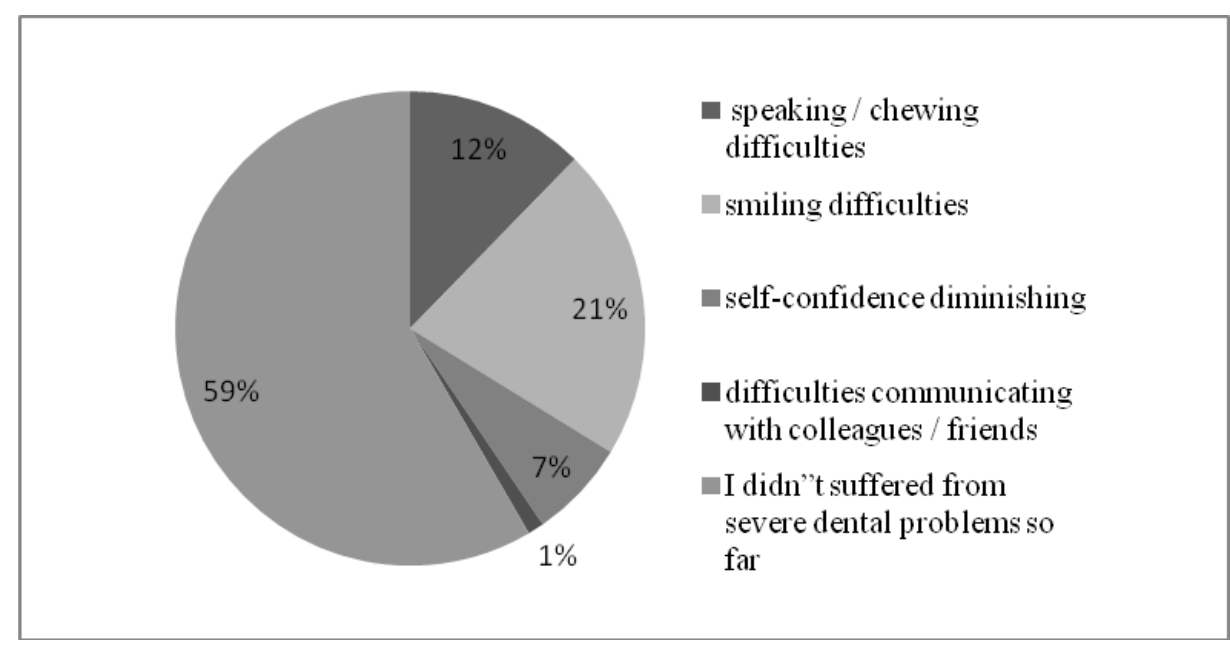

Figure 2. The effects of respondents severe dental diseases

It can be seen also a small percentage of $7 \%$ of those who said the effect of serious dental diseases they suffered is the diminishing of their self-confidence. This effect is a complex one that has direct connection with consumers self image. Diminishing confidence is accompanied in most cases by the alteration of the self-image also (Coon, D., \& Mitterer, J., 2013). The small percentage is eloquent for the situation encountered - a small fraction of respondents are affected currently by dental nature issues from the self-image perspective.

In assessing how social factors influence dental healthcare services consumer behavior is important to stress the link established between the formation of selfimage and the image or perception of others on individuals in terms of dental aesthetics and compliance with social image equivalent across groups with normality. Thus we wanted to determine wheter there is a correlation between the importance given to self-image (as a dependent variable) and variables related with social factors influence 9as independent variables).

In order to highlight the impact of social and economic factors on dental healthcare services consumers' behavior we consider testing these two categories of factors influence upon the importance of consumer self-iamge seen as a mediator for the regulatory pressure of external influences.

In this regard it was initially examined the validity of a regression model obtained as a result of testing the social factors influence on the importance of respondents selfimage during consumption.

To determine the simultaneous influence of independent variables on the dependent variable multiple linear regression was used. The model is of the following form:

$\mathrm{CSMD}=\mathrm{f}(\mathrm{FPCID}, \mathrm{FPCED}, \mathrm{ILM}, \mathrm{TMOZ}, \mathrm{CS}, \mathrm{SS})+\varepsilon$

or

CSMD $=\beta_{0}+\beta_{1} *$ FPCID $+\beta_{2} *$ FPCED $+\beta_{3} *$ ILM $+\beta_{4} *$ TMOZ $+\beta_{5} *$ CS $+\beta_{6} *$ SS $+\varepsilon$

Measurement of all model variables was performed with scaling method called semantic differential scale that leads to the interval type scale. 
family, friends or colegues can influence the decision regarding consumption of a certain dental office services (FPCID)

The importance of the family, friends or colleagues perceptions regarding the dental aesthetic of the consumers (FPCED)

The importance of the consumers image within the workplace from the perspective of dental aesthetic (ILM)

The degree of choosing the dental medical treatment according to the region customs (TMOZ)

Social class can determine the way in which the dental healthcare services are consumed (CS)

Social status can detrmine the way in which the dental healthcare services are consumed (SS)

\section{Figure 3. Graphic model of the social factors influence upon the importance of self-image}

The value for coefficient of multiple correlation $(\mathrm{R})$ is the indicator that summarizes the meaning of the link between variables observed and projected variables based on the regression model for the dependent variable, and in case of the present model, because $\mathrm{R}$ has a value of 0.727 it can be seen that it has a value close to 1 , which indicates that the relationship between the observed and projected values of the dependent variable is strong, which shows the consistency of the model considered.

Another very important coefficient to be abalysed in the case of the linear multiple regression model is the coefficient of multiple determination ( $\mathrm{R}$ squared), which is used to measure the intensity of the relation expressed by the equation of linear regression. The fact that the coefficient has taken value of 0.528 in the present case, means that about $53 \%$ of the variance in the dependent variable is explained by the variation of causal variables, and the remaining of $47 \%$ variation is presented due to the variation of the residual variable $\varepsilon$. Also, the coefficient of multiple determination shows whether multicollinearity exists and therefore this factor must be lower than each of the values of simple correlation coefficients between effect variable and each cause variables. Lack of multicolinearity presuppose that causal variables to be independent. (Malhotra, NK, Birks, DF, \& Wills, PA, 2013)

Table 1. Summary of the information regarding linear multiple regression model

Model summary

\begin{tabular}{|c|c|c|c|c|c|c|c|c|c|c|}
\hline \multirow{2}{*}{$\begin{array}{l}\text { Mod } \\
\text { el }\end{array}$} & \multirow[t]{2}{*}{$\mathrm{R}$} & \multirow{2}{*}{$\begin{array}{c}\mathrm{R} \\
\text { squar } \\
\mathrm{e}\end{array}$} & \multirow{2}{*}{$\begin{array}{l}\text { Adjusted } \\
\text { R square }\end{array}$} & \multirow{2}{*}{$\begin{array}{l}\text { Standard } \\
\text { error of the } \\
\text { estimated } \\
\text { variable }\end{array}$} & \multicolumn{5}{|c|}{ Modified statistics } & \multirow{2}{*}{$\begin{array}{l}\text { Durbin- } \\
\text { Watson }\end{array}$} \\
\hline & & & & & $\begin{array}{c}\text { R square } \\
\text { modificatio } \\
n\end{array}$ & $\begin{array}{c}\mathrm{F} \\
\text { Modificati } \\
\text { on }\end{array}$ & $\begin{array}{c}\text { df1 } \\
\text { (freedom } \\
\text { degrees) }\end{array}$ & $\begin{array}{c}\text { df2 ( } \\
\text { freedom } \\
\text { degrees ) }\end{array}$ & $\begin{array}{l}\text { F statistical } \\
\text { level meaning } \\
\text { modification }\end{array}$ & \\
\hline 1 & $0.727^{\mathrm{a}}$ & 0.528 & 0.520 & 0.346 & 0.528 & 65.062 & 6 & 349 & 0.000 & 2.028 \\
\hline
\end{tabular}


a. Predictors: (Constant), Do you consider that the social status can determine the way in which dental medical services are consumed? How much do you think that the family, friends or colleagues can influence the consumption decision regarding the services of a dental office? How much does it counts for yop the image at your workplace from the perspective of dental aesthetic?, To what extent do you choose the dental medical treatment according to the local customs corresponding to the region you live in?To what extent does it matters for you the way in which family, friends or colleagues are perceveing you from the point of view of dental aesthetic? Do you think that social class can determine how dental healthcare services are consumed? b. The dependent variable: To what extent the dental care services consumption is determined by the importance of self-image for you?

The role of adjusted $\mathrm{R}$ squared coefficient is to measure the impact of causal variables once introduced into the model, as adjusted R squared takes account by the number of independent variables and the sample size. In case of the present model, we can say without fail that the last independent variable introduced into the model produced a significant effect in terms of variation in the dependent variable because it appears that the adjusted $\mathrm{R}$ squared is close to the value of $\mathrm{R}$ square. As the two coefficients $\mathrm{R}$ square and adjusted $\mathrm{R}$ squared values are close, the regression model can be generalized to the entire population subject to the inquiry. Expanding of the envisaged regression model for the entire population studied, would involve a reduction of variance of the dependent variable with a value of 0.008 . This value can be seen that represents less than one percent of the variation like the same variable at the level of entire research sample level.

Analyzing the standard error of the estimated variable, it will show us to what extent there is a residual variable deviation from the average residual variable. The standard error of the estimate for the correlation analyzed amounts to 0.346 , a relatively small value which ensures an appropriate degree of prediction, the model being appropriate in these circumstances.

The statistical $\mathrm{F}$ test provides the possibility to test the statistical significance of the regression model. In the case of $\mathrm{F}$ statistical test, the null hypothesis states that the multiple determination coefficient $\mathrm{R}$ is 0 .

$\mathrm{F}$ changed represents the result of the amendment that is supported by the $\mathrm{F}$ test due to the supplementary variation of $\mathrm{R}$ squared due to the inclusion within the model of the last causal variable.

The value of $\mathrm{F}$ test modification is 65.062 corresponding to a value of (Sig. F Change - change in the level of statistical significance for F) of 0.000 which is less than 0.01 , which means that the value of $\mathrm{F}$ is statistically significant because the possibility that the value of $\mathrm{F}$ to be due to chance is below 0 .

The hypothesis reffering to the absence of residual variable autocorrelation can be tested using the Durbin-Watson statistic. This hypothesis regarding the lack of autocorrelation for the residual variable presupposes that measured errors to be independent.

In order to take into consideration the persistence of the model, the value of DurbinWatson statistic has to be as close as it is possible to the value of 2 . If this will have values closer to 1 or 3 , the revision of the model becomes necessary

For the model related to data analyzed, Durbin Watson statistics value is 2.028. This value allows us to consider the model valid as regards the lack of autocorrelation in residuals.

To determine the predictive ability of the regression model it will be realized the analysis of variance (ANOVA). 
Table 2. The variation analysis for the regression model (ANOVA)

ANOVA $^{\mathrm{a}}$

\begin{tabular}{|rl|r|r|r|r|r|}
\hline Model & Sum of Squares & $\begin{array}{c}\text { Degree of } \\
\text { freedom } \\
(\mathrm{df})\end{array}$ & Mean Square & F & Sig. \\
\hline \multirow{2}{*}{1} & Regresie & 279.578 & 6 & 46.596 & 65.062 & $0.000^{\mathrm{b}}$ \\
& Residual & 249.950 & 349 & 0.716 & & \\
& Total & 529.528 & 355 & & & \\
\hline
\end{tabular}

a. Dependent variable: To what extent the consumption of dental healthcare services is determined by the importance of self-image for you?

b. Predictors: (Constant), Do you consider that the social status can determine the way in which dental healthcare services are consumed?

To what extent do you think that family, friends or colleagues can influence the decision regarding the consumption of dental care services of a particular dental office? How much doest it counts for you your image within the work place from the perspective of dental aesthetic. To what extentdo you choose the dental medical treatment according to the customes of your residence area? To what extent does in counts for you the way that you are perceived by the family, friends or colleagues from the point of view of dental aestethic? Do you consider that the social class can determine the way in which the dental healthcare services are consumed?

If the $\mathrm{F}$ test value exceeds a value of 1 , the predictive ability of the model increases. In case of the present regression model $\mathrm{F}$ value is 65.062 with a probability of error equal to 0.000 , which is implying a high validity of the model and high capacity of prediction of this model. In the following it will be presented the values of estimated coefficients of the regression equation and also their statistical significance.

Table 3. Informations reffering to the value of the regression model estimated coefficients

\begin{tabular}{|c|c|c|c|c|c|c|c|}
\hline \multirow[t]{2}{*}{ Model } & \multicolumn{2}{|c|}{$\begin{array}{l}\text { Unstandardized } \\
\text { coefficients }\end{array}$} & \multirow{2}{*}{$\begin{array}{c}\begin{array}{c}\text { Standardize } \\
\mathrm{d} \\
\text { coefficients }\end{array} \\
\text { Beta }\end{array}$} & \multirow[t]{2}{*}{$\mathrm{t}$} & \multirow[t]{2}{*}{ Sig. } & \multicolumn{2}{|c|}{$\begin{array}{l}\text { 95.0\% Confidence } \\
\text { Interval for B }\end{array}$} \\
\hline & B & Std. Error & & & & $\begin{array}{l}\text { Lower } \\
\text { Bound }\end{array}$ & $\begin{array}{l}\text { Upper } \\
\text { Bound }\end{array}$ \\
\hline (Constant) & -0.579 & 0.317 & & -1.827 & 0.028 & -1.202 & 0.044 \\
\hline $\begin{array}{l}\text { Family, friends or } \\
\text { colegues can influence } \\
\text { the decision regarding } \\
\text { consumption of a certain } \\
\text { dental office services } \\
\text { (FPCID) }\end{array}$ & 0.016 & 0.042 & 0.014 & 0.376 & 0.507 & -0.067 & 0.098 \\
\hline $\begin{array}{l}\text { The importance of the } \\
\text { family, friends or } \\
\text { colleagues perceptions } \\
\text { regarding the dental } \\
\text { aesthetic of the } \\
\text { consumers (FPCED) }\end{array}$ & 0.358 & 0.052 & 0.317 & 6.906 & 0.000 & 0.256 & 0.460 \\
\hline $\begin{array}{l}\text { The importance of the } \\
\text { consumers image within } \\
\text { the workplace from the } \\
\text { perspective of dental } \\
\text { aesthetic (ILM) }\end{array}$ & 0.492 & 0.068 & 0.354 & 7.260 & 0.000 & 0.359 & 0.626 \\
\hline
\end{tabular}




\begin{tabular}{|c|c|c|c|c|c|c|c|}
\hline $\begin{array}{l}\text { The degree of choosing } \\
\text { the dental medical } \\
\text { treatment according to } \\
\text { the region customs } \\
\text { (TMOZ) }\end{array}$ & 0.174 & 0.033 & 0.220 & 5.349 & 0.000 & 0.110 & 0.238 \\
\hline $\begin{array}{l}\text { Social class can } \\
\text { determine the way in } \\
\text { which the dental } \\
\text { healthcare services are } \\
\text { consumed (CS) }\end{array}$ & 0.105 & 0.050 & 0.101 & 2.113 & 0.035 & 0.007 & 0.204 \\
\hline $\begin{array}{l}\text { Social status can } \\
\text { detrmine the way in } \\
\text { which the dental } \\
\text { healthcare services are } \\
\text { consumed (SS) }\end{array}$ & -0.021 & 0.060 & -0.017 & -0.356 & 0.422 & -0.139 & 0.096 \\
\hline
\end{tabular}

a. To what extent the consumption of dental healthcare services is determined by the importance of self-image for you

It has been used the least squares method in order to estimate the regression model parameters values, resulting the following regression equation:

$$
\text { CSMD }=-0.579+0.016 * \text { FPCID }+0.358 * \text { FPCED }+0.492 * \text { ILM }+
$$

$0.174 * \mathrm{TMOZ}+0.105 * \mathrm{CS}-0.021 * \mathrm{SS}$

It may be noted that besides social status variable that has an negative influence on the dependent variable, the other causal variables are influencing in a positive way the dependent variable. Thus, the importance of self-image in dental health services consumption is positively influenced by: the influence of family, friends and colleagues in the decision of choosing a dental office $(+0.016)$; the way that respondents are perceived by family, friends or colleagues in terms of dental aesthetics $(+0.358)$; the importance attached to image within the workplace from the perspective of dental aesthetics $(+0.492)$; area of residence influence on dental medical treatment $(+0.174)$ and social class influence over how dental care services are consumed $(+0.105)$.

The coefficients of the regression equation indicate on one hand the dependent variable sense of influence, and on the other hand the intensity with which these are influencing the dependent variable.

Comparing the regression coefficient values, it appears that most influence is exercised by the variable named importance given to image within workplace from the perspective of dental aesthetics $(+0.492)$ and the variable named the way in which respondents are perceived by family, friends or colleagues from the point of view of dental aesthetics $(+0.358)$.

This means that an amendment with one unit of the importance attached to image within workplace from the dental aesthetics perspective, will increase with 0.492 unites the self-esteem.

In table no. 3 appears the column called Beta that is containing actually the standardized regression coefficients values.

This means that through standardization, continuous variables values are transformed into values of a standardized variable following a normal distribution of mean 0 and standard deviation 1.

Regarding the interpretation of the values, this will be performed similarly to the interpretation of regression coefficients, only if it will be considered a different measure unit, which in case of Beta values, is a standard deviation.

Thus, at the modification with a standard deviation of the variable $\mathrm{x}_{3}$ (importance given to image within the workplace from the dental aesthetics perspective), the 
dependent variable value (consumption of dental health services is determined by the importance of self-image) is changing with 0.354 standard deviations.

The t-Student test is performed in order to check whether the estimated parameter values have a real influence on the dependent variable, which means it must be significantly different from 0 . In the table no 3 it can be seen that out of two parameters (namely those related with independent variables - influence of family, friends and colleagues regarding the decision of choosing a dental office and variable referring to the social status), all other estimated parameters are significantly different from 0 . The probability that the t-Student test value to be due to chance being 0.000 (Sig.). At the same time, it is important to consider which is the magnitude of $t$ Student test value. The value of this test is directly proportional to the influence of the independent variable (related to the regression coefficient for which Student t-test was performed) on the dependent variable.

If we make the comparison between the values of t-Student test it will be found that the maximum value is encountered for the $x_{3}$ variable regression parameter (importance given to image within the workplace from the dental aesthetics perspective) namely 7.260 , which confirms that this variable has the most influence on the dependent variable. For the intercept (the free term, constant), the null hypothesis must be rejected because the significance threshold has the value $\mathrm{p}=$ 0.028 , a value lower than the 0.05 threshold. With a probability of $95 \%$ and a error of 0.317 the intercept is -0.579 . This is situated between the confidence interval [$1.202 ; 0.044]$. For the variable $\mathrm{x}_{3}$ (importance given to image within the workplace from the dental aesthetics perspective) the null Hypothesis $\mathrm{H}_{0}$ must be rejected because the significance threshold $\mathrm{p}=0.000<0.01$. With an error of 0.068 , the ILM coefficient will have the value of 0.492 . This variable can take values in the confidence interval [0.359; 0.626].

So, variables that have a real influence upon the dependent variable (dental healthcare services consumption is determined by the self-image importance) are: importance given to image within the workplace from the dental aesthetics perspective $(t=7.260$, Sig. $=0.000)$; the way that respondents are perceived by the family, friends or colleagues from the point of view of dental aesthetics $(t=6.906$, Sig. $=0.000)$; the residence zone influence upon dental medical treatment $(t=5.349$, Sig. $=0.000)$ and social class influence upon the way in which dental healthcare services are consumed $(\mathrm{t}=2.113$, Sig. $=0.035)$.

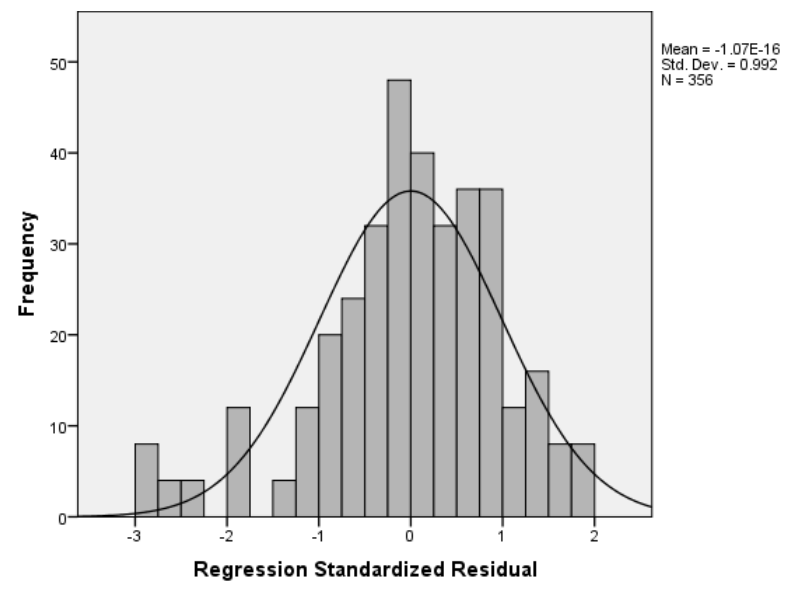

Figure 4. Regression model histogram 
Another objective of the research was to determine the respondents' perception about social class influence on consumers. The given answers have pointed out an average score of 4.079 which means that largely respondents believe that membership to a social class can determine how dental medical services are consumed (about 78\% of the respondents chose the response options reffering to " a large extent” and "a very large extent”).

These results refute the hypothesis $\mathrm{H} 4$, which states that less than $28 \%$ of respondents considers that membership to a certain social class can determine how dental healthcare services are consumed.

These results are eloquent for the perception that Romanian dental healthcare services consumers have about the idea of social class, although this is not very clear defined. The responses shows that the differences related to the consumption of dental healthcare services are associated to a certain social stratification, which on the basis of belonging to a certain class could mean the membership to a certain social group with a specific level of incomes and a specific life style.

The research has as an objective also to determine the perception of respondents towards the influence exerted by the social status upon dental healthcare services consumption.

The received answers are indicating a average score of 4.281 (measured by semantic differential scale with 5 steps), about $85 \%$ of the respondents choosing the response options"very much" and" a lot”.

Thus it becomes evident the consumers perception that is correlated with the one reffering to the social class, namely the consumption of dental healthcare services is influenced by the social position of the individuals, highlighted through class or social status.The social status presuppose asserting and imposing a certain image among social groups of reference. Usually, the social status will be associated with the occupation of individuals, their income, determining the net membership to a certain social group corresponding to the specific status. Also, a certain status implies a series of obligations and rights specific from case to case. The obtained responses confirm also the $\mathrm{H} 5$ hypothesis; because over $46 \%$ of the respondents believe that social status determine a different consumption behavior in case of dental healthcare services.

By correlating the question reffering to the fact that the social status can determine how dental healthcare services are consumed with the one reffering to the income and respectively with the one reffering to the occupation it can be observed that exists a weak correlation between the influence of the social status and the income of respondents and a strong correlation between social status and occupation.

\section{Table 4. Pearson Correlation Coeficient used for correlation between social status and respondents' income verification}

\begin{tabular}{|c|c|c|c|}
\hline & & $\begin{array}{l}\text { Do you think } \\
\text { that social } \\
\text { status can } \\
\text { determine how } \\
\text { dental health } \\
\text { services are } \\
\text { consumed? }\end{array}$ & $\begin{array}{l}\text { Which category } \\
\text { fits your } \\
\text { monthly income }\end{array}$ \\
\hline \multirow{4}{*}{$\begin{array}{l}\text { Do you think that social } \\
\text { status can determine how } \\
\text { dental health services are } \\
\text { consumed? } \\
\text { Which category fits your }\end{array}$} & Pearson Correlation & 1 & 0.399 \\
\hline & Sig. (2-tailed) & & 0.042 \\
\hline & $\mathrm{N}$ & 356 & 356 \\
\hline & Pearson Correlation & 0.399 & 1 \\
\hline
\end{tabular}




\begin{tabular}{|l|r|r|} 
monthly income: & Sig. (2-tailed) & 0.042 \\
$\mathrm{~N}$ & 356 & 356 \\
\hline
\end{tabular}

\section{Table 5. Pearson Correlation Coeficient used for correlation between social status and respondents' occupation verification}

\begin{tabular}{|ll|r|r|}
\hline & $\begin{array}{c}\text { Do you think } \\
\text { that social } \\
\text { status can } \\
\text { determine how } \\
\text { dental health } \\
\text { services are } \\
\text { consumed? }\end{array}$ & $\begin{array}{r}\text { Your } \\
\text { occupation? }\end{array}$ \\
\hline $\begin{array}{l}\text { Do you think that social } \\
\text { status can determine how }\end{array}$ & Pearson Correlation & 1 & $0.743^{* *}$ \\
dental health services are & Sig. (2-tailed) & 356 & 0.007 \\
consumed? & N & $0.743^{* *}$ & 356 \\
Your occupation? & Sig. (2-tailed) & 0.007 & 1 \\
& $\mathrm{~N}$ & 356 & 356 \\
\hline
\end{tabular}

**. Correlation is significant at the 0.01 level (2-tailed).

Correlation analysis reveals that respondents with high incomes not necessarily agree with the fact that social status exerts a strong influence on dental healthcare services consumption behavior, while the opinion of the respondents will be very nuanced according to the occupation they have, so that, about $83 \%$ of those who declared themselves entrepreneurs considered that the status will influence a lot the dental healthcare services consumption behavior, followed by $67 \%$ of those from the category of public figures (presenter, artist etc) and respectively still $67 \%$ from the category of self-employed (freelancers).

These results confirm that the persons that are aware of their social status (those having occupations presupposing a certain financial independence - entrepreneurs, public persons) are convinced of the fact that this is influencing the dental healthcare services consumption behavior. This information may suggest that, in fact, their own behavior is different from the others, being influenced by the social status held.

From the perspective of economic factors influence over the dental healthcare services consumer behavior, the question reffering to the degree in which the consumption of dental care services was affected by the economic crisis, revealed that in a relatively large extent, consumption of dental medical services decreased having in the background the economic crisis (average score of 3.551). In the same register, answers for the question reffering to what extent the consumers have been affected by the prices changing in dental medical services are indicating an average score of 3.506, meaning a relatively strong influence of the prices changes upon the decision to seek dental medical services.

The results based on the analyzed answers are showing a strong influence of the economic nature related factor - income-expenditure ratio in terms of dental healthcare services consumption. 


\section{Conclusions and future research implications}

Putting in common the two types of analysis performed it can be observed that the influence of socioeconomic factors on dental healthcare services consumer behavior is complex, nuanced and subject to a certain dynamics.

The research also revealed the importance of self-image, seen as a real catalyst for the superior level consumer needs. Self-image is correlated with the image of others about the concerned individual, being influenced essentially by two categories of factors: how the individual relates to his internal standards regarding normality, standards developed as a result of education, culture and interactions with the group members respectively the active feedback that persons who will meet the individual will have as an result of human interaction in real time.

The research revealed the way in which the dental aesthetic contributes to the definition of self-image, and thus to the consumption behavior model change, as a result of reactualizations that every individual makes reffering to the others perception upon himself.

Social groups' pression on the consumption behavior is nuanced, because the respondents said they were willing to give up in a small extent to the current dental medical treatment as a result of opinions expressed by the family, friends or colleagues. Thus it is evident the existence of consumption decisions that are dictated by other considerations, different from the need of confirmation with the opinions or actions belonging of the affiliation or reference group.

The workmates opinion and their perception in relation to the individual dental aesthetics represents an important conditioning element of dental care services consumption behavior, thus it appears evident the objective need to comply with the group opinion.

Consumers who have suffered severe dental diseases so far have been affected by the difficulty to smile and to speak or to chew. It exists also a little percent of the people that have declared that the effect of serious diseases was the diminuation of selfconfidence. Thus it becomes evident again the importance of self-image and of interaction with the society from the perspective of dental diseases.

Consumers believe that the social status determine different consumption behaviors. Analysis of the bivariate correlations between status influence and respondents income or their occupation has revealed a weak correlation with the income and a strong one with occupation which indicates that respondents having higher incomes are not necessarily thinking that the social status extert a strong influence upon dental healthcare services consumption behavior, while the opinion of the respondents will be very nuanced according to the occupation they have.

In the light of the results, we can point out some possible future research directions:

- research conducted on a national level with a bigger sample, statistical representative of the social nature influence pointing out the predisposition of the respondents to be influenced by the opinion leaders within reffernce or belonging groups, and the indentification of the leaders that actually have a real influence.

- research of the consumer perception on one hand and the medical staff on the other hand regarding the efficient methods of medical education oriented to dental medical preventive controls and a proper hygiene.

- research upon the perception of general public regarding communication objectives, the communicational ax and the visual identity requested for a social marketing campaign aimed at education in the field of dental medical services.

\section{References}

Baumeister, R. F., Campbell, J. D., Krueger, J. I., \& Vohs, K. D. (2003). "Does high self-esteem cause better performance, interpersonal success, happiness, or 
healthier lifestyles?", Psychological science in the public interest, 4(1), 1-44.

Bearden, W., Netemeyer, R.G., \& Teel, J.E. (1989). "Measurement of Consumer Susceptibility to Interpersonal Influence," Journal of Consumer Research, 15(4), 473-481.

Berkowitz, E.N., Kerin, R.A., Hartley, S.W., \& Rudelius, W. (1992). “Marketing”, 3rd ed., Irwin: Homewood IL.

Ciarrochi, J., Heaven, P. C., \& Davies, F. (2007). "The impact of hope, self-esteem, and attributional style on adolescents' school grades and emotional well-being: A longitudinal study", Journal of Research in Personality, 41(6), 1161-1178.

Coon, D., \& Mitterer, J. (2013). "Introduction to Psychology: Gateways to Mind and Behavior with Concept Maps and Reviews”, Belmont: Cengage Learning

Dittmar, H. (1994). "Material Possessions as Stereotypes: Material Images of Different Socio-Economic Groups", Journal of Economic Psychology, 15(4), 561-585.

Hahn, A.R., \& Harris, W.K. (1999), “Anthropology in Public Health: Bridging Differences in Culture and Society”, New York: Oxford University Press.

Hodgson, G.M. (2003). "The Hidden Persuaders: Institutions and Individuals in Economic Theory", Cambridge Journal of Economics, 27(2), 159-175.

Malhotra N.K., Birks D.F., \& Wills P.A. (2013), “Essentials of Marketing Research”, Harlow: Pearson Education Limited.

Marsh, H.W. (1986). "Global self-esteem: Its relation to specific facets of selfconcept and their importance", Journal of personality and social psychology, 51(6), p. 1224-1236.

Mocean, L. (2012). "The Consumer Behaviour in Social Networks", Marketing From Information to Decision, (5): 274-282.

Reinstaller, A., \& Sanditov, B. (2005). "Social structure and consumption: on the diffusion of consumer good innovation", Journal of evolutionary Economics, 15(5), 505-531.

Sirgy, M. J. (1982). "Self-concept in consumer behavior: A critical review", Journal of consumer research, 9(3), 287-300.

Starr M.A. (2009). "Lifestyle conformity and lifecycle saving: a Veblenian perspective", Cambridge Journal of Economics, 33(1), 25-49

Uskul, A.K. (2010). "Socio-cultural aspects of health and illness", In French, D., Kaptein, A., Vedhara, K., \& Weinman, J., (Eds.). Health psychology. Oxford: Blackwell Publishing.

Vigneron, F., \& Johnson, L.W. (1999), "A review and a conceptual framework of prestige-seeking consumer behavior." Academy of Marketing Science Review, $1(1), 1-15$ 